\begin{tabular}{|c|c|c|}
\hline (1) & $\begin{array}{c}\text { Türkiye Tarımsal Araştırmalar Dergisi } \\
\text { dergipark.org.tr/tutad }\end{array}$ & $\begin{array}{l}\text { Turk J Agric Res } \\
\text { 2020, 7(2): 172-182 } \\
\text { ๑ TÜTAD }\end{array}$ \\
\hline $\begin{array}{l}\text { SilRT } \\
\text { UNiVERSiTESi } \\
\text { Bilimin Nyüunda }\end{array}$ & Araştırma Makalesi / Research Article & $\begin{array}{l}\text { ISSN: } 2148-2306 \\
\text { e-ISSN: } 2528-858 X \\
\text { doi: } 10.19159 / \text { tutad.720139 }\end{array}$ \\
\hline
\end{tabular}

\title{
Tuzlu ve Sodik Arazilerde Islah ve Tarımsal Faaliyetler Sonrası Arazi Tahribatının Dengelenmesinin İzlenmesi
}

\author{
Mesut BUDAK ${ }^{1 *}$, Hikmet GÜNAL ${ }^{2}$, Orhan Mete KILIÇ ${ }^{3}$, Nurullah ACIR ${ }^{4}$

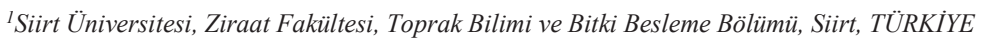 \\ ${ }^{2}$ Gaziosmanpaşa Üniversitesi, Ziraat Fakültesi, Toprak Bilimi ve Bitki Besleme Bölümü, Tokat, TÜRKIYYE \\ ${ }^{3}$ Gaziosmanpaşa Üniversitesi, Fen-Edebiyat Fakültesi, Coğrafya Bölümü, Tokat, TÜRKİYE \\ ${ }^{4}$ Kırşehir Ahi Evran Üniversitesi, Ziraat Fakültesi, Toprak Bilimi ve Bitki Besleme Bölümü, Kırşehir, TÜRKIYYE
}

\begin{tabular}{l}
\hline Geliş Tarihi/Received: $14.04 .2020 \quad$ Kabul Tarihi/Accepted: 30.06 .2020 \\
\hline ORCID ID (Yazar sirasina göre / by author order) \\
(D)orcid.org/0000-0001-5715-1246 (D) orcid.org/0000-0002-4648-2645 (Dorcid.org/0000-0002-6723-1984 (D)orcid.org/0000-0001-7591-0496 \\
${ }^{*}$ Sorumlu Yazar/Corresponding Author: m.budak@siirt.edu.tr
\end{tabular}

Öz: Tarım arazilerinin doğal veya insan kaynaklı etkiler ile bozulmasının önlenmesi ve tahrip olan arazilerin geri kazanımı son zamanlarda birçok ülkenin en önemli stratejik hedefleri arasına girmiştir. Bu kapsamda, arazi tahribatının dengelenmesi (ATD) kavramı, arazi bozulması oranının düşürülmesi ve bozulmuş alanların iyileștirilme oranının artırılmasının göstergesi olarak tanımlanmaktadır. Bir bölgede veya karasal ekosistemde verimli arazi alanı ve dolayısıyla sürdürülebilir arazi kullanımı sabit kaldığında veya arttığında ATD’ye ulașıldığı düşünülebilir. Bu çalıșmada, doğal olarak oluşmus tuzlu/sodik özelliklere sahip merada, sslah faaliyetleri ve sonrası başlatılan tarımsal üretimin etkileri, ATD çerçevesinde değerlendirilmiştir. ATD’nin değerlendirilmesinde, meranın ıslah sonrası tarımsal faaliyetler altındaki üretkenliği, 1slah öncesi ve ıslah sonrası dönemlere ait normalize edilmiş fark bitki örtüsü indeksi (NDVI), net birincil verimlilik (NPP) ile toprak organik karbon stoku (TOCS) verileri kullanılmıștır. Tüm alanda sulama imkânı bulunmadığından yaklaşık 1200 hektarlık alanda ıslah çalıșması yürütülmüştür. Bu kapsamda 2008 ve 2012 yıllarında çalışma alanında 202 noktadan bozulmuş ve bozulmamış toprak örnekleri alınmıstır. Toprak örneklerinin organik madde $(\mathrm{OM})$, hacim ağırlı̆̆ı, toprak reaksiyonu (pH) ve elektriksel iletkenlikleri (EC) belirlenmiș ve değerlendirilmiștir. Islah kapsamındaki arazilerde bașlangıçta ortalama 40.51 ton ha ${ }^{-1}$ olan $^{-2}$ TOCS, 1slah ve tarımsal faaliyetler sonrası 44.68 ton ha-1 ${ }^{-1}$ a çıkmıştır. Islah öncesi -0.044 ile +0.060 ve 125 ile $250 \mathrm{~g} \mathrm{C} \mathrm{m}^{-2}$ arasında olan NDVI ve NPP değerleri, sslah sonrası önemli bir artış göstererek, 2013 ve 2017 yıllarında sırası ile 0.234-0.551 ve $0.419-0.631$ ve $200-475 \mathrm{~g} \mathrm{C} \mathrm{m}^{-2}$ ve $200-407 \mathrm{~g} \mathrm{C} \mathrm{m}^{-2}$ aralığında kayıt edilmiştir. Islah çalışması yürütülen alanlarda islah öncesi ortalama OM değeri \% 2.09 iken, sslah sonrası ortalama \% 2.16'ya çıkmıștır. EC değerleri ise $4.08 \mathrm{dS} \mathrm{m}^{-1}$ 'den $2.26 \mathrm{dS}$ $\mathrm{m}^{-1}$ 'e düşmüştür. Elde edilen bulgular arazi ıslah çalışmalarında benimsenen arazi yönetim uygulamalarının arazi üretkenliğine dolayısı ile ATD'ye olumlu bir etki yaptığını ortaya koymaktadır. Aynı zamanda bu çalıșma, arazi bozulması ve dengelenmesinin izlenmesi için güncel veri tabanlarının önemini de ortaya koymaktadır.

Anahtar Kelimeler: Tuzluluk, sodiklik, Landsat, normalize edilmiş fark bitki örtüsü indeksi, arazi tahribatının dengelenmesi

\section{Monitoring the Land Degradation Neutrality in Saline and Sodic Lands after Reclamation and Agricultural Activities}

Abstract: Prevention of agricultural land degradation due to the natural or anthropogenic impacts and recovery of degraded lands have recently become among the strategic targets of many countries. In this context, the concept of land degradation neutrality (LDN) is defined as an indicator of reducing the rate of land degradation and increasing the rate of improvement in degraded lands. Land degradation neutrality in a region or in the terrestrial ecosystem can be achieved if productive land area and thus sustainable land use remains constant or increases. In this study, the effects of reclamation activities and agricultural production initiated in the pasture, which was naturally occurred with saline/sodic properties, were evaluated within the framework of LDN. In the assessment of LDN, net primary productivity (NPP) of pasture under post-reclamation agricultural activities, the normalized difference vegetation index (NDVI) for pre-reclamation and post-reclamation periods, and soil 
organic carbon stock (TOCS) data were used. Irrigation water was not sufficient for the whole area; therefore, reclamation was carried out in an area of approximately 1200 ha. In this context, disturbed and undisturbed soil samples were taken from 202 points of the study area in 2008 and 2012. Organic matter (OM), bulk density, soil reaction $(\mathrm{pH})$ and electrical conductivity (EC) of soil samples were determined and evaluated. The mean TOCS content of the study area in the pre-reclamation period was 40.51 tons ha-1, while it was increased to 44.68 tons ha-1 after the reclamation and agricultural activities. The NDVI and NPP values, which were between -0.044 and +0.060 and 125 and $250 \mathrm{~g} \mathrm{C} \mathrm{m}^{-2}$ in pre-reclamation period, increased to 0.419 - 0.631 and $0.234-0.551$; and $200-475 \mathrm{~g} \mathrm{C} \mathrm{m}^{-2}$ and $200-407 \mathrm{~g} \mathrm{C} \mathrm{m}^{-2}$ after the reclamation and agricultural activities in 2013 and 2017, respectively. The mean OM content of the study area in the pre-reclamation period was $2.09 \%$ and the OM content increased to $2.16 \%$ in the pre-reclamation period. The EC values decreased from $4.08 \mathrm{dS} \mathrm{m}^{-1}$ to $2.26 \mathrm{dS} \mathrm{m} \mathrm{m}^{-1}$. The findings of the study indicated that land management practices adopted in the land reclamation had a positive impact on land productivity as well as to the LDN. In addition, this study reveals the importance of updated databases for monitoring land degradation and neutrality.

Keywords: Salinity, sodicity, Landsat, normalized difference vegetation index (NDVI), land degradation neutrality

\section{Giriș}

Toprağın fonksiyonlarını yerine getirebilme kapasitesinde meydana gelen azalma olarak tanımlanan arazi bozulmasının (tahribatının) boyutu; fonksiyonların yerine getirilmesinde etkili olan fiziksel, kimyasal ve biyolojik toprak özelliklerinin belirlenmesi ile ifade edilmektedir. Arazi bozulması, aynı zamanda bitki örtüsünün yoğunluğunda, yapısında, tür kompozisyonunda veya verimliliğinde geçici veya kalıcı bir azalma olarak tanımlanan bitki örtüsü tahribatını da kapsamaktadır (Grainger, 2015). Zira arazinin fiziksel, kimyasal ve biyolojik yapısında meydana gelen değişiklik arazinin üretebilme kapasitesinin de azalmasına neden olacaktır.

Verimlilik, Birleşmiş Milletler'in "Sürdürülebilir Kalkınma Hedefleri”nde dikkate aldığı ve daha geniş kapsamda bir "tarımsal verimlilik" terimi kavramına dahil ettiği bir toprak özelliğidir (Tóth ve ark., 2018). Kurak ve yarı kurak iklim bölgelerinde arazi bozulmasına ve zamanla verimliliğin kaybolmasına neden olan en temel işlemler, toprakta tuz ve değişebilir sodyum (Na) içeriğinin yükselmesi ile ortaya çıkan tuzluluk ve sodikliktir (Qadir ve ark., 2014). Bitki kök bölgesindeki eriyebilir tuzların yıkanmasına yetecek kadar yağışın olmadığ 1 kurak bölgelerde, tuzluluk ve sodiklik bitki gelişimini sınırlandırmakta, bitki tür ve sayısının azalmasına neden olmaktadır (Faritfeh ve ark., 2005; Liu ve ark., 2017).

Kurak ve yarı kurak bölgelerde, su kaynaklarının yetersizliği yanı sıra tarım arazilerinde görülen tuzluluk, geçim kaynağı tarımsal ve hayvansal üretim olan toplumlar için gıda güvenliğini tehdit eden en önemli sorunların başında gelmektedir (Cowie ve ark., 2018). Son zamanlarda oluşan gıda güvenliği endişeleri yanı sıra tarımsal üretime açılabilecek yeni verimli arazilerin azlığı, bozulmuş arazilerin verimliliğinin artırılmasının önemini siyasi gündeme taşımıştır. $\mathrm{Bu}$ nedenle, tuzluluktan etkilenen araziler dahi düşük ürün verimlerine rağmen, ihmal edilemeyecek veya kolayca terk edilemeyecek değerli araziler olarak görülmektedir (Qadir ve ark., 2014).

Bozulmuş arazilerde sürdürülebilir gıda üretimini desteklemek için arazilerin sslah edilmesi veya uygun koşullar olduğunda doğal veya yarı doğal durumuna geri getirilmesi gerekmektedir (Sujatha ve ark., 2019). Bu kapsamda, arazi bozulmasına neden olan etmenlerin doğru bir şekilde belirlenmesi ve buna göre uygun 1slah yöntemlerinin geliştirilmesi kritik önem taşımaktadır. Nitekim arazi bozulmasının yönetimi, gıda güvenliğinin sağlanması ve sürdürülebilir geçim kaynaklarının arttırılmasının yanı sıra iklim değişikliğinin hafifletilmesi ve biyolojik çeşitliliğin korunması açısından da fayda sağlamaktadır (Cowie ve ark., 2018). Bunun bilincinde olan uluslararası kurullar, arazi bozulması ile mücadelede, çeşitli coğrafyalarda gerçekleşen arazi bozulmalarına uyarlanabilir yaklaşımlar üzerine odaklanmışlardır. Bu konuda ülkeleri çölleşme ile mücadele konusunda çalışmalar yapmaya teşvik eden Birleşmiş Milletler, arazi bozulmasının iyileştirilmesi ile dengelenmesi (Arazi Tahribatının Dengelenmesi, ATD; Land Degradation Neutrality, LDN) yaklaşımını önemli hedeflerinden biri olarak belirlemiştir. Arazi Tahribatının Dengelenmesi, "Ekosistemimin işlevlerini ve hizmetlerini desteklemek ve gıda güvenliğini arttırmak için gerekli olan arazi kaynaklarının miktarının ve niteliğinin sabit kaldığ 1 veya belirtilen zamansal ve mekânsal ölçekler kapsamında artış göstermesi” şeklinde tanımlanmıştır (Anonymous, 2016). Dolayısı ile ATD, sağlıklı ve üretkenlik kapasitesi yüksek arazilerin verimliliklerini korumak ve bu arazilerde herhangi bir kaybın olmadığı kararlı bir duruma ulaşmak için arazi bozulmasını önlemek/azaltmak veya mevcut bozulmayı tersine çevirmek için uygun yönetim sistemlerinin geliştirilmesi ve gerekli tedbirlerin alınması amacını gütmektedir (Anonim, 2020a). Arazi bozulmasının dengelenmesi hedefine ulaşmak için 
yapılacak eylemler arasında, bozulmayı önleyen veya azaltan arazi yönetim yaklaşımlarının benimsenmesi ve üretkenliğini kaybetmiş olan arazilerin restorasyonu veya rehabilitasyonu yoluyla geri dönüşümü tersine çevirme çabaları da yer almaktadır (Sujatha ve ark., 2019).

Bugüne kadar ATD ile ilgili yapılan çalışmalarda arazi yönetim planlamalarının, arazilerin üretkenliği üzerindeki etkisinin (iyileşme veya gerileme) takip edilebilmesi için; arazideki bitki örtüsü değişimi, arazi üretkenliği [gösterge: Net Birincil Verimlilik (Net Primary Productivity, NPP)] ve toprak organik karbon stoku (TOCS) değerlerinin göz önünde bulundurulması gerektiği rapor edilmiştir (Anonymous, 2016; Gilbey ve ark., 2019; Dengiz ve ark., 2020; Kiani-Harchegani ve Sadeghi, 2020). Bai ve ark. (2008), herhangi bir bölgedeki arazi bozulmasının Normalize Edilmiş Fark Bitki Örtüsü İndeksi (Normalized Difference Vegetation Index, NDVI) ve NPP değerlerinden yararlanılarak tahmin edilebileceğini ve arazi kullanım yöntemlerinin arazi bozulmasına yol açıp açmadığ ${ }_{1}$ konusunda bilgi sahibi olunabileceğini rapor etmişlerdir. Toprakta mevcut organik maddenin toprağa katılan organik maddeden daha hızlı ayrışması durumunda, NPP değerlerinin azalacağı ve nihayetinde arazi bozulmasının görüleceği rapor edilmiştir (Haberl ve ark., 2001). $\mathrm{Bu}$ çalışmada, doğal olarak oluşmuş tuzlu/sodik özelliklere sahip mera alanlarında, sslah faaliyetleri sonrası, başlatılan tarımsal üretimin ATD çerçevesinde değerlendirilmesi amaçlanmıştır.

\section{Materyal ve Yöntem}

\section{1. Çalışma alanının tanımı ve bazı özellikleri}

Çalışma alanı; kurak bir iklime sahip Niğde ili Bor ilçesi Kızılca beldesinin güneyinde, 617000624000 doğu boylamları ile 4177000-4188000 kuzey enlemleri arasında yer alan yaklaşık 2650 hektar büyüklüğündeki mera arazilerdir (Şekil 1). Uzun yıllar (1935-2018) ortalama iklim verilerine göre Niğde ilinin ortalama yıllık yağış miktarı 341.4 $\mathrm{mm}$ ve ortalama hava sicaklığ $11.2{ }^{\circ} \mathrm{C}$ 'dir (Anonim, 2020b). Ancak Niğde il merkezine göre daha çukur bir topoğrafyada yer alan çalışma alanında, 2009 yılında tesis edilen iklim verilerinin son 10 yıllık verilerine göre yıllık ortalama toplam yağış miktarı sadece 220.6 mm'dir.

Çalışma alanında, Aridisol toprak ordosunda sınıflandırılmış 7 farklı toprak serisi tanımlanmıştır. Yüksek tuz ve sodyum içeriğine sahip olan arazinin önemli bir kısmı tuzlu ve sodik olarak rapor edilmiştir (Budak, 2012). Çalışma alanının yüzey $(0-30 \mathrm{~cm})$ katmanında toprak reaksiyonu $(\mathrm{pH}) 7.51$ ile 9.31 ve elektriksel iletkenlik (EC) 0.61 ile 27.40 dS $\mathrm{m}^{-1}$ arasında olduğu bildirilmiştir. Aynı derinlikte toprakların sodyum adsorpsiyon oran1 (SAR) 0.23 ile 98.23 ve değișebilir sodyum yüzdesi (\% ESP) ise 0.49 ile 54.82 arasında değişim gösterdiği belirlenmiştir. Doğal bir mera alanı olarak kullanılan çalışma alanında yüksek tuz içeriği nedeniyle çoğunlukla halofit (tuzcul) bitkilerin yetiştiği tespit edilmiştir (Budak, 2012).
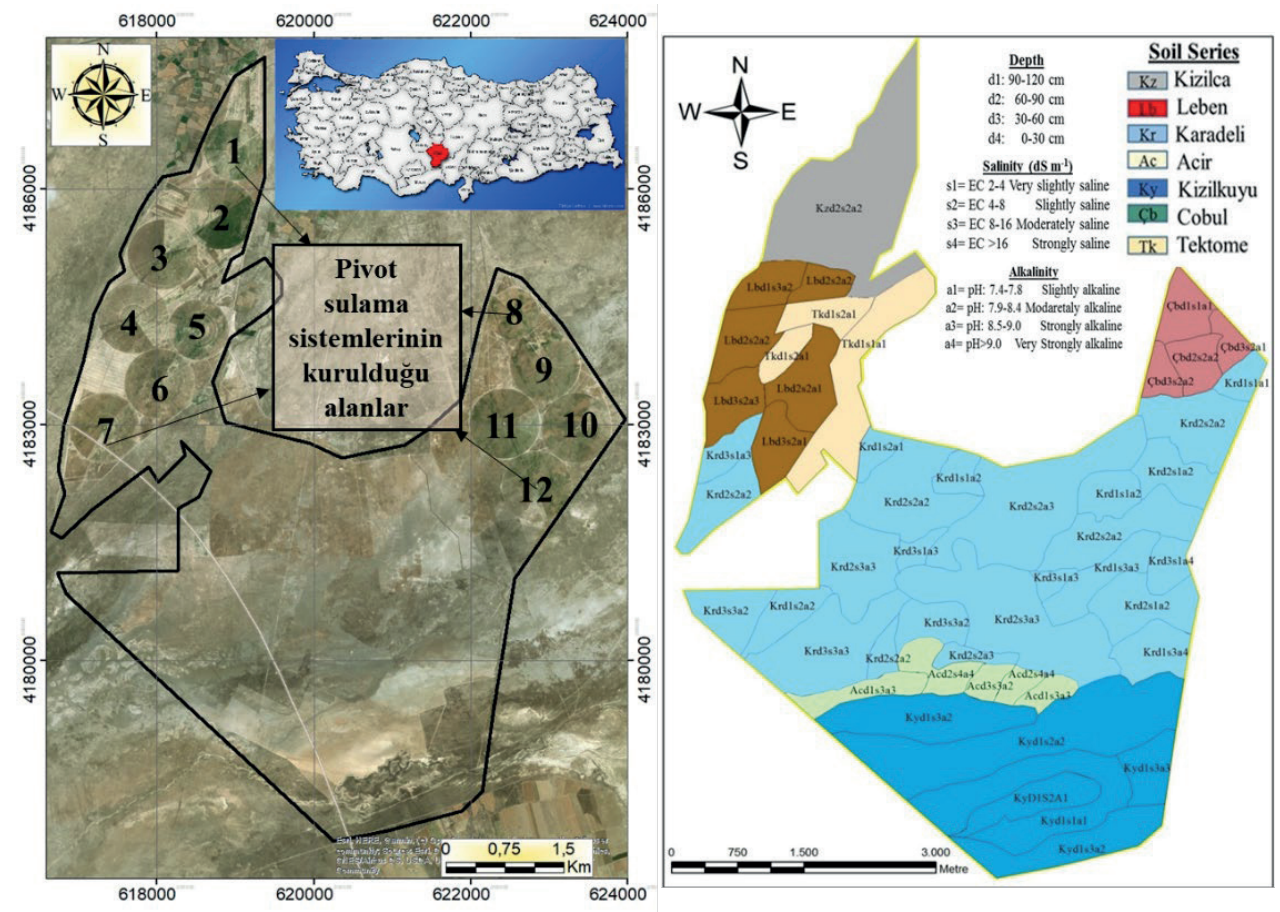

Şekil 1. Çalışma alanının konumu ve toprak seri haritası (Budak, 2012) 
Çalışma alanında 2009 yılı yaz döneminde ıslah çalışmaları başlatılmıştır. Öncellikle geçirgenliği arttırmak ve yıkanmayı kolaylaştırmak adına, alanın tamamında farklı derinlikler ve kalınlıklarda olduğu tespit edilen sert katmanlar (petrokalsik horizonu) riperler ile patlatılmaya çalışılmıştır. Daha ince ve yüzeysel olan katmanlar parçalanırken, derin ve kalın olan katmanlara etki edilememiştir. $\mathrm{Bu}$ kapsamda, çalışma alanının büyük çoğunluğu derin sürüm şeklinde işlenmiştir. Arazinin 1slahı kapsamında, değișebilir sodyum yüzdesinin durumunu dikkate alarak değişen oranlarda jips uygulaması yapılmıştır. Çalışma alanın tamamında sulama imkânı bulunmadığından alanının kuzey kısmında yer alan Kızılca, Leben, Tektome, Çobul serileri ile Karadeli serisinin kuzey kısımlarında yer alan yaklaşık 1200 hektar alanda ıslah çalışması ve bitkisel üretim faaliyetleri yürütülmüştür (Şekil 1). Islah çalışmaları kapsamında, sadece tuzun yüksek $\mathrm{Na}$ konsantrasyonunun düşük olduğu alanlarda tavalar oluşturulmuş ve yıkamalar yapılarak tuzun uzaklaştırılması sağlanmıștır. Çalışılan alanın genişliği ve bölgede su kaynaklarının yetersiz olması nedeni ile yıkama faaliyetleri yaklaşı 50 hektarlık bir bölümde yapılabilmiştir. Bitkisel üretimin yapıldığg diğer tüm arazilerde her sulamada yıkama suyu ihtiyacının fazlası verilerek tuzların bitki kök bölgesinin altına inmesi sağlanmıştır. Çalışma alanında, bitkisel üretim yapılması planlanan tüm arazilere ortalama 2 ton ha ${ }^{1}$ olacak şekilde elementel kükürt ve 6 ton ha $^{-1}$ büyük baş hayvan gübresi ilk 4 yıl içerisinde uygulanmıştır (Şekil 2). Hayvan gübresi uygulaması, sürekli bir şekilde devam etmektedir.

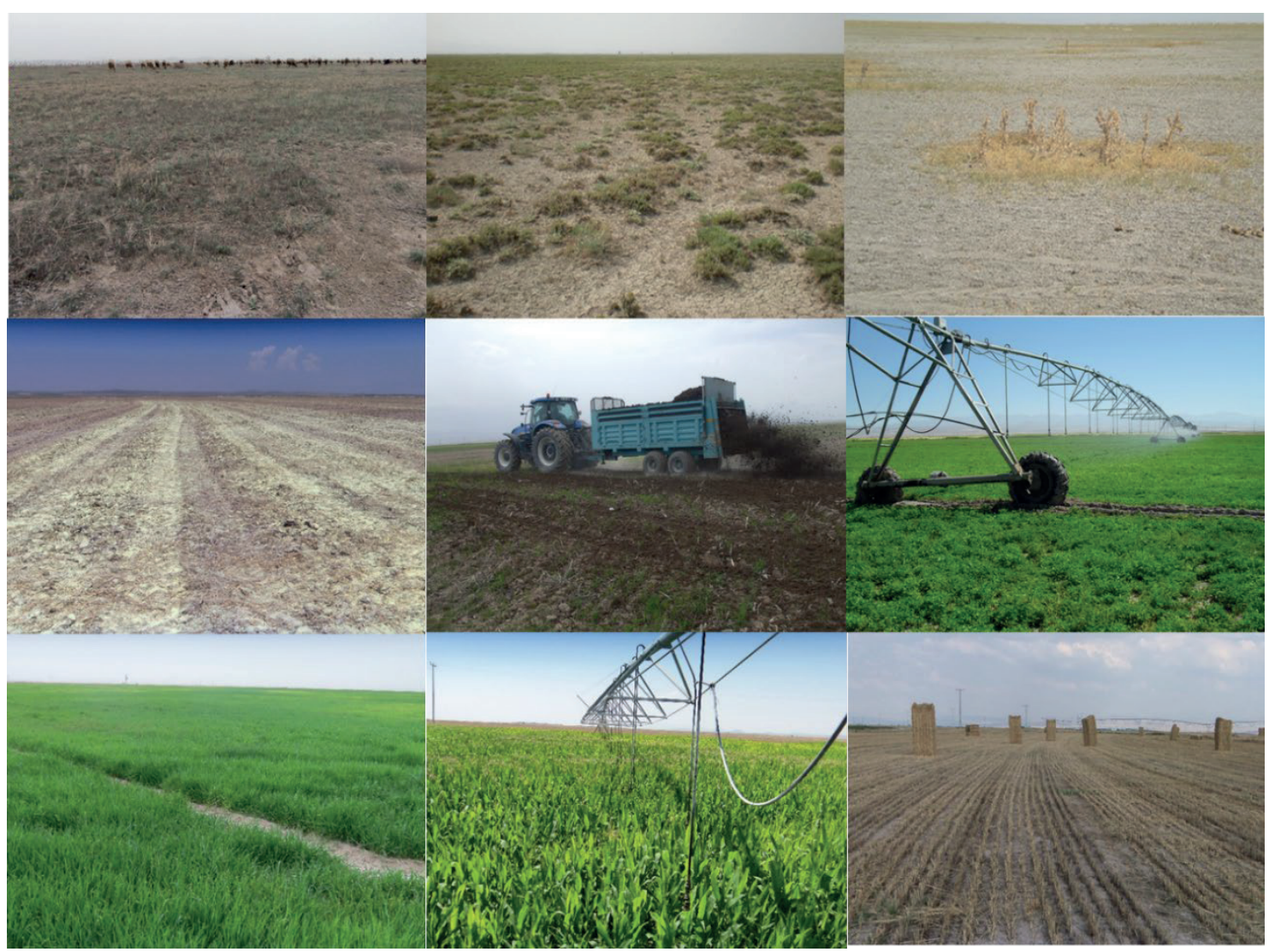

Şekil 2. Çalışma alanın ıslah öncesi ve sonrası görüntüleri

Çalıșma alanının yaklașık 1000 hektarlık kısmına "center pivot" yağmurlama sulama sistemleri tesis edilmiştir. $\mathrm{Bu}$ büyük sulama sistemlerinin ulaşamadığı alanlara ise (yaklaşık 200 ha) çeşitli yağmurlama sulama ve damlama sulama sistemleri tesis edilerek tarımsal üretime başlanmıştır. Başlangıçta, alandaki tuz ve bor konsantrasyonları dikkate alınarak; çavdar, tritikale ve arpa tarımı yapılmış ve özellikle bahar aylarında sulama gereksinimi, tesis edilen sulama sitemleri kullanılarak karşılanmıştır (Şekil 2). 


\subsection{NDVI verilerinin belirlenmesi ve haritalanması}

Çalışma alanına ait 2009, 2013 ve 2017 y1llarının Landsat uydu görüntüleri https:/earthexplorer.usgs.gov/ internet adresinden indirilmiştir. Çalışmada kullanılan uydu görüntüleri ait detaylı bilgiler Tablo 1'de verilmiştir. Landsat görüntüleri, $30 \mathrm{~m}$ x $30 \mathrm{~m}$ çözünürlükte veriler içerdiğinden, bu görüntülerim işlenmesi ile üretilen NDVI verileri de aynı çözünürlükte olmuştur. Çalışma alanına ait uydu verileri ArcGIS paket programında yer alan spatial analiz (Spatial Analysis Tolls)-harita cebiri (Map Algebra)-raster hesaplama (Raster Calculator) modülleri ile analiz edilmiş ve Eşitlik 1 kullanılarak NDVI değerleri hesaplanmış ve haritalanmıştır.

$$
N D V I=\frac{(N I R-R E D)}{(N I R+R E D)}
$$

Eşitlikte NIR, yakın kızılötesi dalga boyu yansıma değerini; RED ise kırmızı bölge dalga boyu yansıma değerini ifade etmektedir (Ali ve ark., 2019; Yadav ve Borona, 2019).

Tablo 1. Çalışma alanı uydu verilerine ait bazı bilgiler

\begin{tabular}{llcc}
\hline Y1 & Uydu & Tarih & Kullanilan Bant \\
\hline 2009 & Landsat 4-5 TM 176/34 & 02.04 .2009 & Bant 3- Bant 4 \\
2013 & Landsat 8 OLI/TIRS 176/34 & 13.04 .2013 & Bant 4- Bant 5 \\
2017 & Landsat 8 OLI/TIRS 176/34 & 24.04 .2017 & Bant 4- Bant 5 \\
\hline
\end{tabular}

\subsection{NPP değerlerinin belirlenmesi ve haritalanması}

Çalışmada kullanılan temel NPP veri seti, Amerika Birleşik Devletleri Ulusal Havacılık ve Uzay Dairesi (NASA) tarafindan sağlanan verilerdir. Modis uydusu Terra sensoru tarafından 8 günlük döngülerle kayıt edilen verilerden MOD17A3HGF algoritmas1 kullanılarak hazırlanan yıllık NPP veri seti içerisinden, NASA'nın resmi internet ortamından çalıșma alanına ait 2009, 2013 ve 2017 yıllarının Modis NPP uydu görüntüleri indirilmiştir. Veriler, "Modis Yeniden Projeksiyonlardırma Aracı" (MRTMODIS Reprojection Tool) kullanılarak UTM (Universal Transversal Mercator Projection) projeksiyon sisteminde Datum, WGS 1984; zon numarası, 36 şeklinde koordinatlandırılmıștır. Çalışma alanı sınır haritası kullanılarak maskelenen veri setleri düzeltme faktörü ile çarpılarak NPP değerleri $\mathrm{kg} \mathrm{C} \mathrm{m}^{-2}$ olarak oluşturulmuştur. Daha sonra veri setleri 1000 kat sayısı ile çarpılarak sahanın g C m ${ }^{-2}$ NPP veri seti hazırlanmıștır (Yan ve ark., 2018). Çalışmada kullanılan bütün uzaktan algılama verileri $30 \mathrm{~m}$ çözünürlükle olduğundan NPP haritasının çözünürlüğü de 500 m'den 30 m olacak şekilde arttırılmıştır. Elde edilen NPP değerleri ArcGIS paket programı yardımı ile analiz edilerek haritalanmıştır.

\subsection{TOCS verilerinin belirlenmesi ve haritalanması}

Çalışma alanına ait toprakların TOCS içerikleri, 1slah öncesi ve 1slah sonrası organik madde ve hacim ağırlığı içerikleri göz önünde bulundurularak Eşitlik 2'ye göre belirlenmiștir. Islah öncesi 2008 yılına ait organik madde ve hacim ağırlığı verileri
Budak (2012) ve 1slah sonrası 2012 y1lı verileri ise Acir (2014)'den temin edilmiştir.

$$
\text { TOCS }=h a * D * T O C * A
$$

Eşitlikte $h a, 0-30 \mathrm{~cm}$ toprak derinliğindeki toprağın hacim ağırlığını $\left(\mathrm{Mg} \mathrm{m}^{-3}\right) ; \mathrm{D}$, toprak örneğinin alındığı derinliğini (m); TOC, Walkey Black metoduna göre elde edilen toprak organik $\mathrm{C}$ miktarını $\left(\mathrm{g} \mathrm{kg}^{-1}\right) ; A$, alanın genişliğini $\left(10^{4}\right)$ temsil etmektedir (Zhang ve ark., 2013).

\section{Bulgular ve Tartışma}

Arazi ıslah çalışmalarının verimlilik üzerine pozitif veya negatif ektisi, ATD’nin önemli göstergeleri olan bitki örtüsü değişimi (arazi kullanım değişimi veya NDVI değerleri), biyokütle miktarı (NPP) ve TOCS ile ilişkilendirilmektedir (Chasek ve ark., 2019). Bu çalışmada, çoğunlukla tuzlu sodik karakterdeki çalışma alanında, yıkama, jips, elementel kükürt, hayvan gübresi kullanımı ve bitkisel üretim ile arazi yüzeyinin sürekli örtülü bulundurulması şeklindeki uygulamaların arazi verimliliği üzerindeki etkisi ATD çerçevesinde değerlendirilmiştir. $\mathrm{Bu}$ kapsamda yapılan değerlendirmeler sonucunda elde edilen 2008 ve 2012 y1llarına ait TOCS değerleri ile 2009-2013 ve 2017 yıllarına ait NPP ve NDVI değerlerine ait ait tanımlayıc1 istatistikler Tablo 2'de, değişim haritaları ise Şekil 3-5'te verilmiştir. Çalışma alanında toprak örneklemeleri ıslah öncesi 2008 ve 1slah sonrası ise 2012 yılında yapılmıştır. Bu nedenle TOCS ile ilgili değerlendirmeler sadece 2008 ve 2012 yılı için yapılmıştır. Arazi kullanımındaki değişimi belirlemek için ise https://earthexplorer.usgs.gov/ adresinden 2008 ve 2012 yılları Nisan ayına ait uygun uydu verileri elde edilmediğinden 1slah öncesi için 2009 ve 1slah 
Tablo 2. Çalışma alanı için farklı yıllara ait NDVI ve NPP değerleri

\begin{tabular}{ccccccc}
\hline Parametre & Ylllar & En küçük & En büyük & Ortalama & $\begin{array}{c}\text { Standart } \\
\text { sapma }\end{array}$ & $\begin{array}{c}\text { Varyasyon } \\
\text { katsay1s1 (\%) }\end{array}$ \\
\hline \multirow{2}{*}{ NDVI } & 2009 & -0.044 & 0.382 & 0.020 & 0.041 & 205.00 \\
& 2013 & 0.031 & 0.551 & 0.258 & 0.089 & 34.50 \\
& 2017 & -0.034 & 0.631 & 0.200 & 0.145 & 72.50 \\
\hline \multirow{2}{*}{ NPP } & 2009 & 125.04 & 266.86 & 180.33 & 22.74 & 12.61 \\
$\left(\mathrm{~g} \mathrm{C} \mathrm{m}^{-2}\right)$ & 2013 & 188.02 & 474.76 & 279.90 & 64.62 & 23.09 \\
& 2017 & 127.08 & 406.74 & 213.61 & 71.92 & 33.67 \\
\hline TOCS $\left._{(\text {ton ha }}^{-1}\right)$ & 2008 & 7.62 & 84.91 & 37.67 & 13.63 & 36.18 \\
\hline
\end{tabular}

sonrası için 2013 ve 2017 y1lı uydu verileri kullanılarak değerlendirmeler yapılmıştır.

Islah öncesi doğal bir mera alanı olarak çoğunlukla koyunların otlatılmasında kullanılan çalışma alanında, TOCS içeriği 7.62 ton $\mathrm{ha}^{-1}$ ile 84.91 ton $\mathrm{ha}^{-1}$ arasında değişmiştir. Islah öncesi ortalama 37.67 ton $\mathrm{ha}^{-1}$ olan TOCS, 1slah sonras1 ortalama 39.28 ton $\mathrm{ha}^{-1}$, a çıkmıştır. Islah sonrasında tüm alanda TOCS değerleri ise 12.10 ton ha $^{-1}$ ile 88.18 ton $\mathrm{ha}^{-1}$ arasında değişim göstermiştir (Tablo 2, Şekil 3). Özellikle kurak iklime sahip bölgelerde ortaya çıkan arazi bozulmasının tersine dönüştürülmesi için yapılan iyileştirme faaliyetlerinin TOC kaybını azalttığı ve arazideki bozulmayı tersine çevrilebildiği rapor edilmiştir (Chasek ve ark. 2019). İklim değişikliği ile mücadelede en önemli stratejik hedef toprakta organik karbon (C) stokunun arttırılıp atmosferdeki $\mathrm{C}$ konsantrasyonunun azaltılmasıdır. Lu ve Liao
(2017) bir bölgedeki tarımsal amenajman yöntemlerinin (bitki yetiştiriciliği, toprak işleme, gübreleme sulama vb.) koşullara bağlı olarak toprak karbonunun, kalitesi ve miktarına olumlu veya olumsuz etki edebileceğini bildirmişlerdir. Özellikle yapılan yanlış uygulamalardan dolayı arazilerde görülen tahribatlar TOC miktarının azalmasına neden olmaktadır. Ancak, çalışma alanında da görüldüğü gibi, arazi ıslahı öncesinde tuz ve yüksek $\mathrm{Na}$ nedeniyle bitkilerin yeterince gelişemediği ve kontrolsüz otlatma nedeniyle biyokütle katılımının gerçekleşmediği arazilerde; toprak koşullarının iyileşmesi, hayvan gübresi ilavesi ve bitkisel üretim ile birlikte büyük miktarda bitki atığının ilavesi arazide toprak sağlığının iyileşmesine olumlu katkı yapabilmektedir. Kucharik ve ark. (2001), yanlış arazi kullanım planlamalarından dolayı arazi sahiplerinin neden olduğu TOC kaybının oldukça yüksek olduğunu ve bu kaybın topraktaki C miktarının yaklaşık

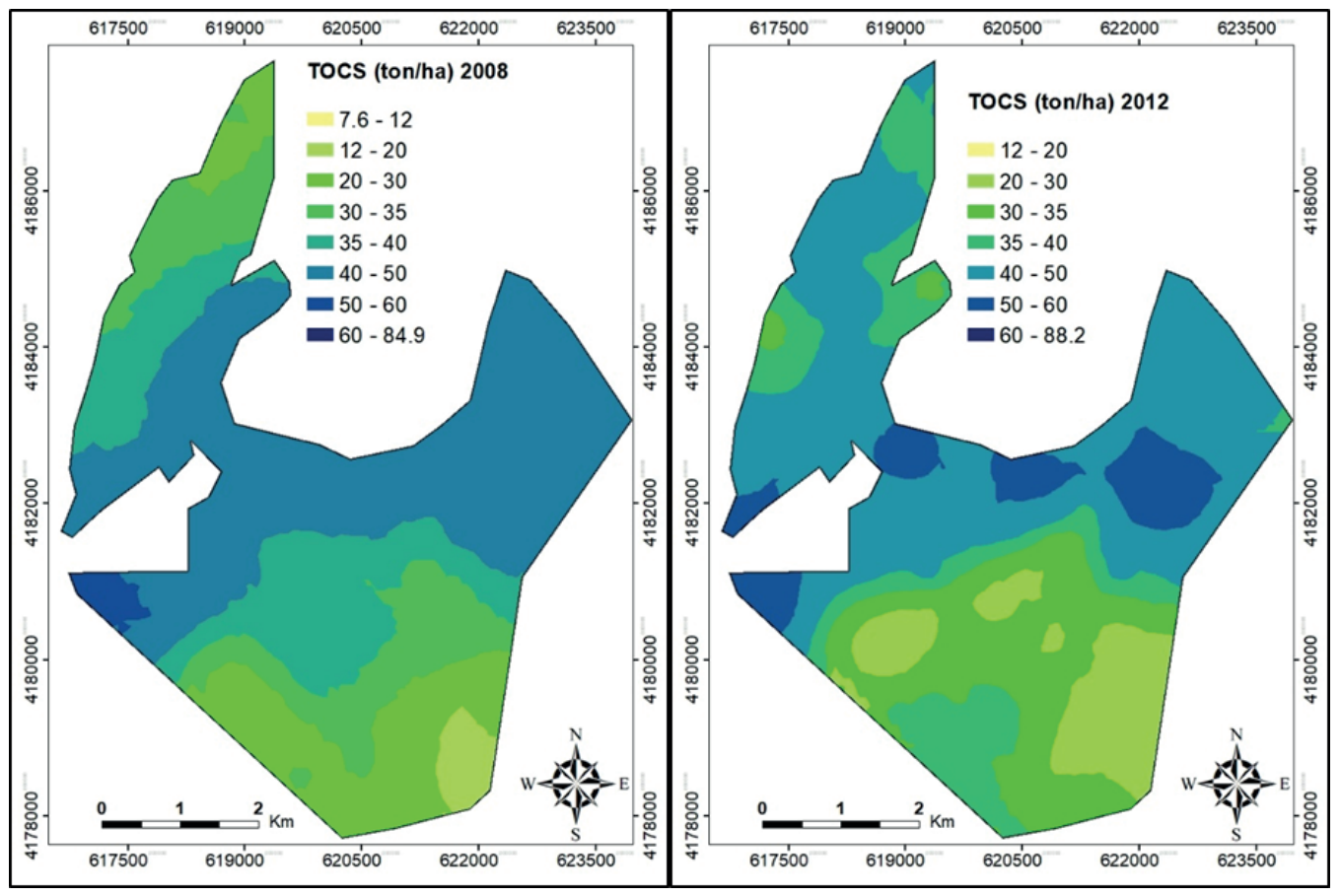

Şekil 3. 2008 ve 2012 yıllarına ait çalışma alanı TOCS değişim haritaları 
\% 63'üne kadar çıktığını bildirmişlerdir. Ancak bu çalışmada elde edilen bulgular sslah yapılan alanlarda toprak organik $\mathrm{C}$ içeriğinin önemli düzeyde arttığını göstermektedir. Çalışma alanında bitkisel üretimin yapılabildiği alanda 1slah öncesi TOCS içerikleri ortalama 40.51 ton ha ${ }^{-1}$ iken, islah sonrası bu değerin 44.68 ton ha ${ }^{-1}$, a çıktığ 1 tespit edilmiştir. Ayrıca ıslah öncesinde ortalama \% 2.09 olan organik madde içeriği (Budak, 2012), 1slah sonrası ortalama \% 2.16'a yükselmiştir (Acir, 2015).

$\mathrm{Bu}$ durum, 1slah çalışmaları ve tarımsal üretim faaliyetleri için benimsenen uygulamaların ATD'ne olumlu etki ettiğine işaret etmektedir. Toprak organik C stoku için elde edilen dağılım haritaları incelendiğinde, 1slah çalışmalarının yürütüldüğü alanın kuzey kısımlarında ıslah öncesine göre TOCS içeriğinin önemli derecede artış gösterdiği tespit edilmiştir (Şekil 3).

NDVI değerleri, bitki büyüme karakteristiklerinin en temel göstergelerinden biri olarak kabul edilmekte ve toprak verimliliğindeki değişimlere bağlı olarak değişkenlik göstermektedir (Hansen ve ark., 2009). Genel olarak NDVI değerleri (-1) ile (+1) arasında değişim göstermekte olup, değerin +1 'e yaklaşması yeşil bitki örtüsünün artışına, 0'a yaklaşması ise yeşil bitki örtüsünün azalmasına işaret etmektedir. NDVI değerlerinin eksi olduğu durumlar ise su yüzeyi ile ilişkilendirilmektedir (Buchhorn ve ark., 2016). Çalışma alanı 2009, 2013 ve 2017 yılları için NDVI değerleri sirası ile ortalama $0.020,0.258$ ve 0.200'dür (Tablo 2). Islah sonrası NDVI değerlerinin ılah öncesine göre yaklaşık 10 kat artmasının en önemli nedeni, toprak tuzluluğunun azalması ile arazi yüzeyinin buğday, arpa, çavdar, mısır ve yonca gibi bitkilerle kapalı bulunmasıdır. Çalışma alanında ıslah çalışmalarının yürütüldüğü kuzey k1smında islahtan önce EC değerleri ortalama $4.08 \mathrm{dS} \mathrm{m}^{-1}$ iken (Budak, 2012) 1slahtan sonra ortalama EC değeri $2.26 \mathrm{dS} \mathrm{m}^{-1}$, e düşmüştür (Acir, 2015). Tuzlu bir toprakta buğday yetiştiriciliğinde toprak özelliklerinden $\mathrm{pH}, \mathrm{EC}$ ve bitki verimlilik parametrelerinden 1000 tane ağırlığının NDVI değerleri ile önemli bir ilişkiye sahip olduğu ve NDVI değerlerinin toprağın verimliliğini yansıtan önemli bir gösterge olduğu bildirilmiştir (Ali ve ark., 2019). Pan ve ark. (2013) yaptığı çalışmada NDVI ile EC arasinda negatif $(r=-0.78)$, NDVI ile organik $\mathrm{C}$ arasında ise yüksek düzeyde pozitif $(r=0.892)$ bir ilişki olduğunu rapor etmişlerdir. Aynı çalışmada toprak tuzluluğunun takip edilmesi açısından NDVI değerlerinin önemli bir gösterge olduğu bildirilmiştir.

Çalışma alanının NDVI için oluşturulan dağılım haritaları incelendiğinde sslah çalışmasından önce en düşük NDVI değerlerine sahip $(-0.044-+0.060)$ arazilerin kuzey kısımda olduğu görülmektedir. Ancak 1slah çalışmasından sonra 2013 ve 2017 yıllarında bu alan en yüksek NDVI (0.234 - 0.551 ve 0.419 - 0.631) değerlerini almıştır (Şekil 4). Özellikle de bitkisel üretimin yapıldığı alanın kuzey kısımlarında NDVI değerleri 2013 yılında yer yer 0.551 'e ve 2017 yılında 0.631 'e kadar yükselmiştir. Gichenje ve Godinho (2018), Kenya'da arazi bozulmasının dengelenmesi kapsamın 1992-2015 yılları arasında uydu görüntülerinden elde ettikleri NDVI değerlerini incelemiş ve belirli bir zaman aralığında arazi verimliliğindeki değişimin belirleneceğini ve buna göre arazi yönetim uygulamalarının geliştirilebileceğini rapor etmişlerdir. $\mathrm{Bu}$ çalışmada elde edilen NDVI değerleri, kurak bölgelerde özellikle tuzluluk gibi bitki gelişimini sınırlandıran sorunların olduğu arazilerin, doğal hallerine bırakılmaktansa islah edilip korumalı tarımsal üretim gerçekleştirilmesinin ATD adına önemli olduğunu göstermektedir.

Arazilerin üretkenlikleri, NPP verilerinin yorumlanması ile siniflandirılabilmektedir (Ateşoğlu ve Şenyaz, 2018). Lal (2014) de ekosistemlerin izlenmesinde NPP'nin önemli bir gösterge olduğunu bildirmiştir. Çalışma alanı için yapılan değerlendirmede 2009, 2013 ve 2017 yıllarına ait ortalama NPP değerleri sırası ile 180.33 $\mathrm{g} \mathrm{C} \mathrm{m}^{-2}, 279.90 \mathrm{~g} \mathrm{C} \mathrm{m}^{-2}$ ve $213.61 \mathrm{~g} \mathrm{C} \mathrm{m}^{-2}$ olduğu görülmektedir. Islah öncesi çalışma alanında en yüksek NPP değeri $266.86 \mathrm{~g} \mathrm{C} \mathrm{m}^{-2}$ iken, 2013 yılında $474.76 \mathrm{~g} \mathrm{C} \mathrm{m}^{-2}$ ve 2017 yılında $406.74 \mathrm{~g} \mathrm{C}$ $\mathrm{m}^{-2}$ olarak ölçülmüştür (Tablo 2, Şekil 5). Niğde iline ait 3 farklı yıl için yıllık toplam yağış miktarları ile NPP değerleri karşılaştırıldığında yıllık ortalama yağışın yüksek olduğu 2009 (460.8 mm) y1lında NPP değerlerinin düşük olduğu, yağışın azaldığı 2013 (311.6 mm) ve 2017 (266.5 $\mathrm{mm}$ ) (Anonim 2020c, 2020d) yıllarinda ise NPP değerlerinin daha yüksek olduğu görülmüştür. Yağışın yüksek olmasına rağmen, NPP değerinde 2009 yilında görülen düşük değerlerin temel nedeni tuzluluk ve sodiklikten dolayı görülen arazi bozulması ve beraberinde ortaya çıkan üretkenlik kaybıdır. Zira NPP için oluşturulan dağılım haritaları incelendiğinde çalışma alanının kuzey kısımlarında ıslah çalışması öncesi NPP değerleri 125-250 g C m${ }^{-2}$ arasında değişim gösterirken, 1slahtan sonra 2013 yılında 200-475 $\mathrm{g} \mathrm{C} \mathrm{m}^{-2}$ ve 2017 yılında 200-407 g C m $\mathrm{m}^{-2}$ arasında değişim göstermiştir (Şekil 5). Arazi tahribatının dengelenmesi kapsamında değerlendirildiğinde, yağış miktarı azalmasına rağmen NPP'deki artış arazi kullanım yöntemlerinin arazi üretkenliği üzerine pozitif bir etki oluşturduğunu ortaya koymaktadır. Ayrıca NPP'ya ait dağılım haritaları 
incelendiğinde 1slah yapılmayan arazilerde, y1llık ortalama yağışın yüksek olduğu 2009 yılında NPP değerlerinin yüksek olduğu, yağışın azaldığı 2017 yılında ise NPP değerinin azaldığı görülmektedir. $\mathrm{Bu}$ çalışmada elde edilen bulguları destekler mahiyette, Cowie ve ark. (2018), yağış deseni ile tutarsız bir ilişki içinde olan NPP'deki kaybın arazi bozulmasının önemli bir göstergesi olduğunu bildirmişlerdir. Araștırmacılar, NPP'deki artıșı ise restorasyon veya rehabilitasyon çalışmalarının başarısı ile ilişkilendirmişlerdir. Nitekim aynı araştırmacılar yağış rejimi ile beraber NPP değerlerinin karşılaştırılmasının, arazi bozulma durumu ve riskinin izlenmesi ve uygun amenajman yöntemlerinin geliştirilmesi açısından uzmanlara kolaylıklar sağladığını rapor etmiştir.

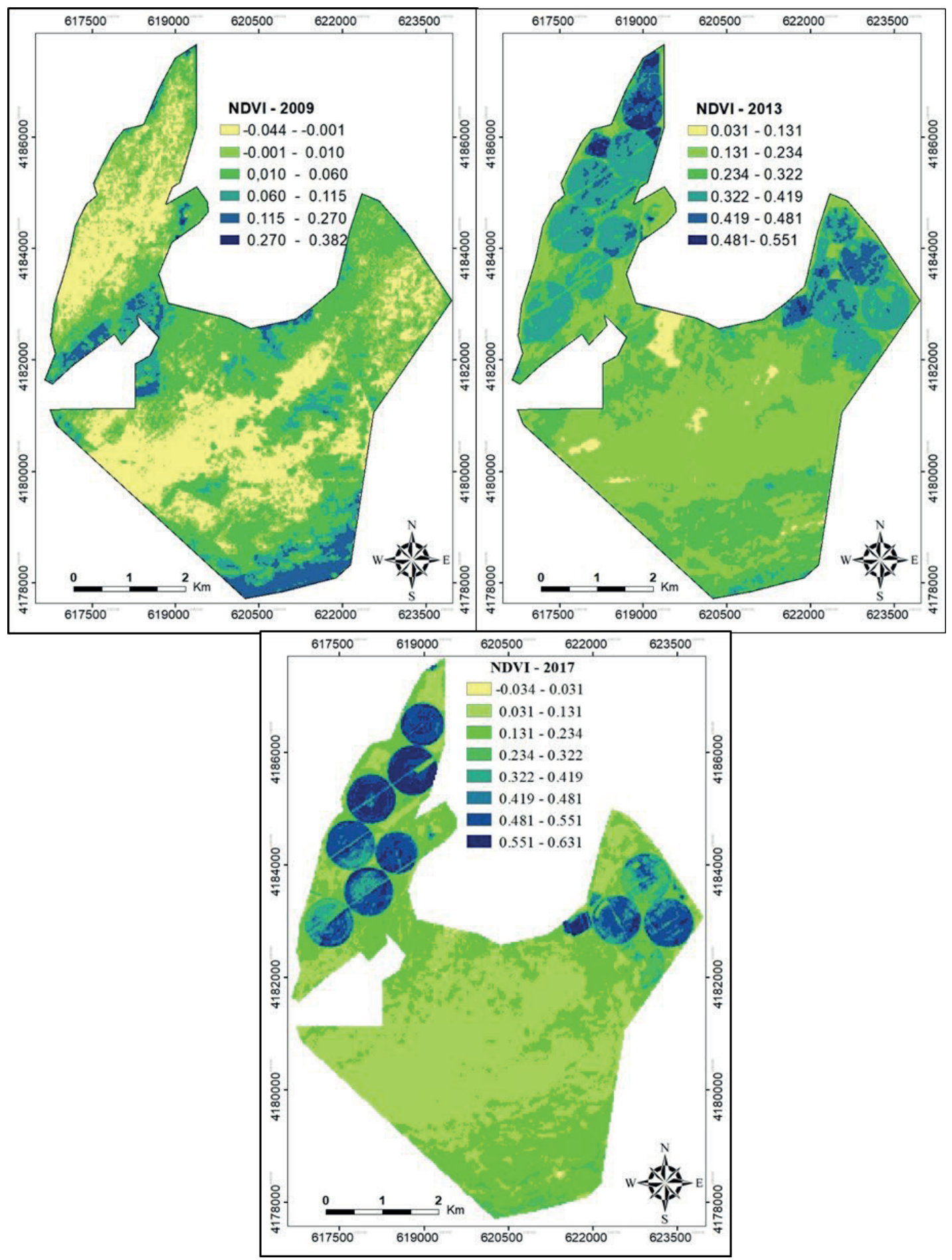

Şekil 4. Çalışma alanın farklı yıllar için NDVI değerleri ait değişim haritaları 


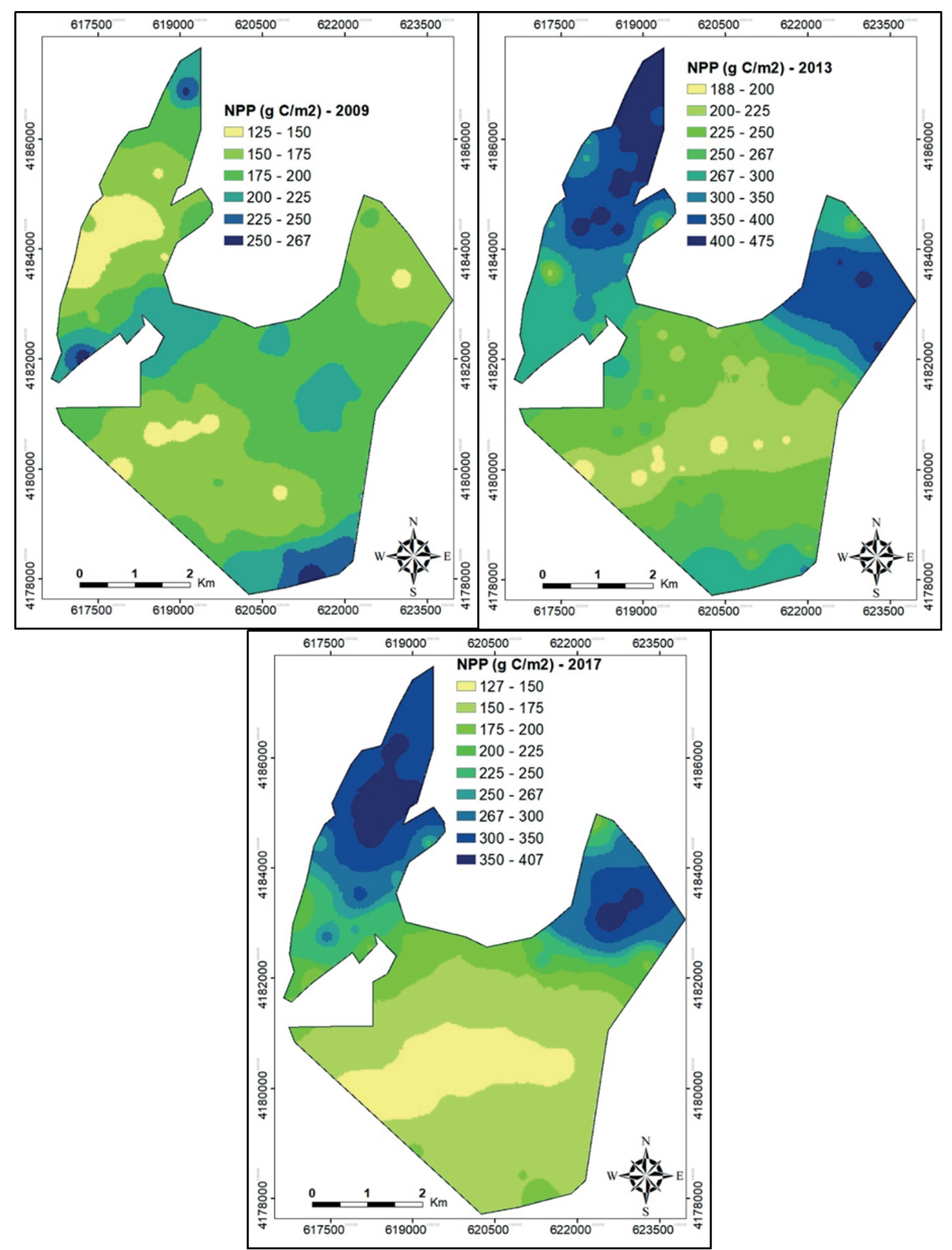

Şekil 5. Çalışma alanı arazilerinin farklı yıllara ait NPP değerleri değişim haritaları

\section{Sonuçlar}

Arazi kullanımının zaten çok yoğun olduğu alanlarda kullanımın daha da yoğunlaştırılması, bozulmayı hızlandırabilir ve arazinin tarım üretim kabiliyetinin tamamen kaybolmasına neden olabilir. Ancak, bu çalışmanın gerçekleştirildiği araziler gibi çeşitli nedenlerle üretkenliklerini kaybetmiş arazilerde, var olan sorunların düzeltilmesi sonrası korumalı tarım altında yoğun bir şekilde kullanımları üretkenliklerinin daha da artmasına neden olmuştur. Araştırma sonuçları, kurak ve yarı kurak bölgelerde yer alan sorunlu arazilerde, iyi tarım uygulamaları ile toprağın organik karbon 
stoku (TOCS) miktarının arttırılabileceğini bununda arazi yüzeyindeki bitki örtüsünün artmasına ve arazinin net birincil üretkenliğinin (NPP) iyileşmesine neden olacağını göstermiştir. Bu çalışma, Birleşmiş Milletler' in 2030 yılına kadar ulaşılmasını arzu ettiği, Sürdürülebilir Gelişme Hedefleri arasında yer alan, "çölleşmeyle mücadele, çölleşme ve kuraklıktan ve taşkınlardan etkilenen arazilerde dâhil olmak üzere bozulmuş arazileri ve toprakları geri kazanmak ve arazi bozulumundan bağımsız bir dünya" hedefinin ulaşılabilir olduğunu göstermektedir.

$\mathrm{Bu}$ çalışmada elde edilen sonuçlar tuzluluk/sodiklik nedeniyle bozulmanın görüldüğü arazilerde arazi tahribatının dengelenmesi göstergelerinin, uygulamaların sonuçlarının değerlendirilmesinde önemli birer parametre olduğunu göstermektedir. Ayrıca bulgular NDVI, NPP ve TOCS değerlerinin arazilerde görülen mevcut bozulma durumlarının ve gelecekteki değişimlerinin ortaya konulmasında yöneticilere ve arazi planlayıcılarına önemli bilgiler sunduğunu ortaya koymaktadır. Ancak arazi verimliliğindeki değişimin sağlıklı bir şekilde izlenebilmesi ve uygun yönetim sistemlerinin geliştirilmesi için arazi tahribatının başlangıç ve zaman içindeki değişimi ile ilgili verilere ihtiyaç duyulmaktadır. Bu nedenle, konu ile ilgili verilerin yer aldığ 1 mevcut veri tabanların güncellenmesi ve yeni veri tabanlarının oluşturulması gerekmektedir.

\section{Teșekkür}

$\mathrm{Bu}$ çalışmada kullanılan 2008 yılı verilerine ait analizler, Gaziosmanpaşa Üniversitesi Bilimsel Araştırma Projeleri Koordinatörlüğü tarafından desteklenen "GOÜ-2011/101" no'lu proje kapsamında yapılmıştır. Ayrıca arazi çalışmaları Cıngıllı Organik Tarım İşletmeleri Anonim Şirketi tarafından desteklenmiştir.

\section{Kaynaklar}

Acir, N., 2014. Kurak ve yarı-kurak bölge topraklarının toprak kalitesinin belirlenmesinde kullanılacak minimum veri setlerinin hazırlanmasi. Doktora tezi, Gaziosmanpaşa Üniversitesi Fen Bilimleri Enstitüsü, Tokat.

Ali, R.R., El-Kadera, A.A., Essaa, E.F., Abdel Rahman, M.A., 2019. Application of remote sensing to determine spatial changes in soil properties and wheat productivity under salinity stress. Plant Arch, 1(19): 616-621.

Anonim, 2020a. Ülke Düzeyinde Arazi Tahribatının Dengelenmesi ATD Hedef Belirlemenin Yap1 Taşları. (https://www.tarimorman.gov.tr/CEM/Belge ler/yay\%C4\%B1nlar/yay\%C4\%B1nlar\%202017/AT DxHedefxBelirlemexTasxTRxm.pdf), (Erişim tarihi: 05.03.2020).
Anonim, 2020b. Niğde İli İklim verileri. (https://www. mgm.gov.tr/veridegerlendirme/il-ve-ilceler-statistik. aspx?k=A\&m=NIGDE), (Erişim tarihi: 10.03.2020).

Anonim, 2020c. Niğde İli 2013 Y1lı Çevre Durum Raporu. (https://webdosya.csb.gov.tr/db/ced/editor dosya/Nigde_icdr2013.pdf), (Erişim tarihi: 22.03.2020).

Anonim, 2020d. Niğde 2017 Yılı Yağış Miktarı. (http://www.nigde.gov.tr/cografi-yapi), (Erişim tarihi: 22.03.2020).

Anonymous, 2015. Convention to Combat Desertification and the Intergovernmental. Report of the Conference of the Parties on its 12th Session, 12 to 23 October 2015, Ankara, p. 3-24.

Ateşoğlu, A., Şenyaz, A., 2018. Arazi tahribatının dengelenmesi bilimsel kavram çerçevesi kapsamında Collect Earth metodolojisinin değerlendirilmesi. VII. Uzaktan Algilama-CBS Sempozyumu (UZAL-CBS 2018), 18-21 Eylül, Eskişehir, s. 1-13.

Bai, Z.G., Dent, D.L., Olsson, L., Schaepman, M.E., 2008. Proxy global assessment of land degradation. Soil Use and Management, 24(3): 223-234.

Buchhorn, M., Raynolds, M.K., Walker, D.A., 2016. Influence of BRDF on NDVI and biomass estimations of Alaska Arctic tundra. Environmental Research Letters, 11(12): 125002.

Budak, M., 2012. Tuzlu alkali toprakların oluşumu, sinıflandırılması ve klasik toprak etüt ve jeoistatistik yöntemlerle haritalanmasi. Doktora Tezi, Gaziosmanpaşa Üniversitesi Fen Bilimleri Enstitüsü, Tokat.

Chasek, P., Akhtar-Schuster, M., Orr, B.J., Luise, A., Ratsimba, H.R., Safriel, U., 2019. Land degradation neutrality: The science-policy interface from the UNCCD to national implementation. Environmental Science \& Policy, 92: 182-190.

Cowie, A.L., Orr, B.J., Sanchez, V.M.C., Chasek, P., Crossman, N.D., Erlewein, A., Louwagie, C., Maron, M., Metternicht, G., Minelli, S., Tengberg, A.E., Walter, S., Welton, S., 2018. Land in balance: The scientific conceptual framework for Land Degradation Neutrality. Environmental Science \& Policy, 79: 25-35.

Dengiz, O., Öztaş, T., Haliloğlu M., Şahin, N., 2020. Arazi tahribatının dengelenmesi. Türkiye Ziraat Mühendisliği IX. Teknik Kongresi, Tam Metin Bildiri Kitab1,13-17 Ocak, Ankara s. 81-104.

Faritfeh, J., Farshad, A., George, R.J., 2005. Assessing salt-affected soils using remote sensing, solute modelling, and geophysics. Geoderma, 130(3-4): 191-206.

Gichenje, H., Godinho, S., 2018. Establishing a land degradation neutrality national baseline through trend analysis of GIMMS NDVI time-series. Land Degradation \& Development, 29(9): 2985-2997.

Gilbey, B., Davies, J., Metternicht, G., Magero, C., 2019. Taking land degradation neutrality from concept to practice: Early reflections on LDN target setting and planning. Environmental Science \& Policy, 100: 230237. 
Grainger, A., 2015. Is land degradation neutrality feasible in dry areas? Journal of Arid Environments, 112: 1424.

Haberl, H., Erb, K.H., Krausmann, F., 2001. How to calculate and interpret ecological footprints for long periods of time: the case of Austria 1926-1995. Ecological Economics, 38(1): 25-45.

Hansen, M.K., Brown, D.J., Dennison, P.E., Graves, S.A., Bricklemyer, R.S., 2009. Inductively mapping expert-derived soil-landscape units within dambo wetland catenae using multispectral and topographic data. Geoderma, 150(1-2): 72-84.

Kiani-Harchegani, M., Sadeghi, S.H., 2020. Practicing land degradation neutrality (LDN) approach in the Shazand Watershed, Iran. Science of the Total Environment, 698: 1-11.

Kucharik, C.J., Brye, K.R., Norman, J.M., Foley, J.A., Gower, S.T., Bundy, L.G., 2001. Measurements and modeling of carbon and nitrogen cycling in agroecosystems of southern Wisconsin: potential for SOC sequestration during the next 50 years. Ecosystems, 4(3): 237-258.

Lal, R., 2014. Soil conservation and ecosystem services. International Soil and Water Conservation Research, 2(3): 36-47.

Liu, G.M., Zhang, X.C., Wang, X.P., Shao, H.B., Yang, J.S., Wang, X.P., 2017. Soil enzymes as indicators of saline soil fertility under various soil amendments. Agriculture Ecosystems \& Environment, 237: 274279.

Lu, X., Liao, Y., 2017. Effect of tillage practices on net carbon flux and economic parameters from farmland on the Loess Plateau in China. Journal of Cleaner Production, 162: 1617-1624.

Pan, C., Zhao, H., Zhao, X., Han, H., Wang, Y., Li, J.,
2013. Biophysical properties as determinants for soil organic carbon and total nitrogen in grassland salinization. PloS One, 8(1): 1-6

Qadir, M., Quillérou, E., Nangia, V., Murtaza, G., Singh, M., Thomas, R.J., Drechsel, P., Noble, A.D., 2014. Economics of salt-induced land degradation and restoration. Natural Resources Forum, 38: 282-295.

Sujatha, G., Mitran, T., Tummala, K., Janaki Rama Suresh, K.G., Fyzee, M.A., Sreenivas, K., Ravisankar, T., 2019. A decision based approach to develop action plans for land degradation neutrality using geospatial techniques in a semi-arid region of India. Journal of Geomatics, 13(2): 188-194.

Tóth, G., Hermann, T., Da Silva, M.R., Montanarella, L., 2018. Monitoring soil for sustainable development and land degradation neutrality. Environmental Monitoring and Assessment, 190(2): 1-4.

Yadav, S.K., Borana, S.L., 2019. Modis derived NDVI based time series analysis of vegetation in the Jodhpur Area. ISPRS-GEOGLAM-ISRS Joint International Workshop on "Earth Observations for Agricultural Monitoring”, The International Archives of the Photogrammetry, Remote Sensing and Spatial Information Sciences, Volume XLII3/W6, 18-20 February, New Delhi, India, p. 535-539.

Yan, Y., Liu, X., Ou, J., Li, X., Wen, Y., 2018. Assimilating multi-source remotely sensed data into a light use efficiency model for net primary productivity estimation. International Journal of Applied Earth Observation and Geoinformation, 72: 11-25.

Zhang, M.Y., Wang, F.J., Chen, F., Malemela, M.P., Zhang, H.L., 2013. Comparison of three tillage systems in the wheat-maize system on carbon sequestration in the North China Plain. Journal of Cleaner Production, 54: 101-107. 